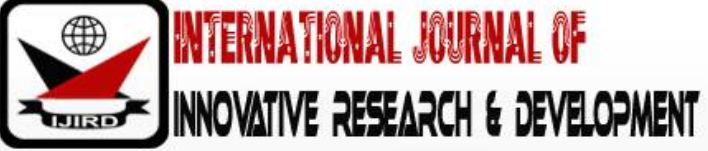

ISSN 2278 - 0211 (Online)

\section{Knowledge and Awareness of Cervical Cancer among Students of a Tertiary Institution in Southern Nigeria.}

\author{
Dr. Mac-Fiberesima Gborieneomie \\ Chief Medical Laboratory Scientist, Department of Medical Microbiology/ Parasitology, \\ University of Port Harcourt Teaching Hospital, Nigeria \\ Dr. Sally Nkechinyere Ibe \\ Lecturer, Department of Public Health, Federal University of Technology Owerri, Nigeria
}

\begin{abstract}
:
Introduction: Cervical cancer is a disease of the female genital tract causing serious health challenge especially among the child bearing age in economically depressed countries. Women aged $\geq 15$ years in Nigeria are at risk of developing cervical cancer and the disease incidence in Nigeria among women is 250/100,000. Assessing the knowledge and awareness of cervical cancer of tertiary students will be of immense contribution in management and prevention of the disease. The aim of this study was to assess cervical cancer awareness among University of Port Harcourt students in Nigeria. Method: Across sectional descriptive study design was employed to systematically sample330 female students using the multi-stage sampling technique. Data was collected using a validated structured closed ended questionnaire. Statistical package for social sciences version 21 was used to analyze the data and hypothesis was tested using chi square at $\mathrm{P} \leq 0.05$. Results: An average level awareness $(50.91 \%)$ for cervical cancer $(\mathrm{p}=0.05)$ was recorded. The mean standard deviation was $4.17 \pm 2.41$.Majority of the respondents were within the age of 18-21(30.91\%). Level of study mostly involved was level one (32.12\%). Singles demonstrated a higher proportion (68.48\%) and respondent's religious affiliation was $100 \%$ for Christianity. An awareness practice disconnect was observed which can promote cervical cancer transmission within the population. Consistent health education is needed by the population to increase their awareness and knowledge. Conclusion: There is need to improve awareness through cervical cancer education, inclusion of cervical cancer screening for females as part of pre-school screening test and formation of cervical cancer clubs on campuses. A national cervical cancer algorithm is also advocated.
\end{abstract}

Keywords: Awareness, cervical cancer, knowledge, prevention and risk factors

\section{Introduction}

Cervical cancer is one of the cancers suffered globally by young women especially in the child bearing age in the developing and under developed countries (Masood., 1999) and second most commonly found cancer among women in Nigeria (Gorollet al., 1995). According to Pisaniet al., (1999), 36.59 million women aged $\geq 15$ years in Nigeria are at risk of developing cervical cancer and the disease incidence in Nigeria among women is $250 / 100,000$. The health status of female under graduate students constitutes an important socio economic aspect and development of any country. Therefore, assessing their knowledge and awareness of cervical cancer will be of immense contribution in management and prevention of the disease. Researchers have reported that Human papilloma virus infection is one of the risk factors responsible for cervical cancer infection which constitutes up to $90 \%$ of invasive cervical cancer and related to $80 \%$ of the pre cancerous changes in the cervix globally (Walboomerset al., 1999) and directly due to infection with HPV-16 and 18 strains thus making it the only human cancer with known causative agent (Munoz et al., 2003; Anorlu., 2008; Walboomerset al., 1999).

It was estimated that every year 14,550 women are diagnosed with cervical cancer and 9,659 die from the disease. It is Projected that in 2025, there will be 22,914 new cervical cancer cases and 15,251 cervical cancer deaths in Nigeria (WHO, 2010). The national Age standardized incidence rate for cervical cancer in Nigeria was estimated to be 33.0 cases per 100,000 women per year (WHO, 2010). In spite of the fact that cervical cancer is preventable and treatable, many women are neither aware nor knowledgeable about the route of contact, the signs and symptoms, and ways of preventing it. A number corresponding to three quarter of cervical cancer patients are diagnosed at advanced stages leading to poor prospects of long-term survival and cure. This is as a result of the non-existence of a national algorithm for screening cervical cancer, lack of infrastructure, inadequately trained health staff, inability to access health early, poor knowledge about the risk factors, and huge presumed financial cost for screening. Consequently, a significant public health burden is ensured as the attendant loss of lives is needless due to its preventable and treatable nature (WHO, 2006). Awareness and knowledge is currently viewed as the most effective approach for cervical cancer control which will ultimately reduce the incidence and mortality from the disease (WHO, 2006). 
Knowledge and awareness of cervical cancer is the foundation for the basis of designing successful preventive strategies. Risk factors for cervical cancer include early age of first sexual exposure, bleeding during sexual intercourse, multiple sexual partners, smoking and immune suppression (Hendricks, 2003). Although the mean age of diagnosis is 50 years, women as young as 17 years who are already sexually matured can also develop the disease with the highest risk group being 25-49 years (WHO, 2006). Awareness about new screening and cervical cancer prevention methods remains low among most women, with studies recording almost no awareness of HPV infection or cervical cancer screening and adolescent vaccination for the prevention of future disease (Lenselinket al., 2008). This study is therefore aimed to determine the level of knowledge and awareness of cervical cancer prevention among female tertiary undergraduate students in Rivers State. It is expected that the findings of this study would help to increase awareness and knowledge thus suggest appropriate interventions to foster improved early health assessment habit among women and also encourage parents to vaccinate their daughters against cervical cancer early in life.

\section{Materials and Methods}

\subsection{Study Design}

This study adopts a cross sectional descriptive study. The design is appropriate for the study as it permits the collection of original data from the respondents to investigate the problem.

\subsection{Area of Study}

The study was conducted in University of Port Harcourt Choba, in ObioAkpor Local Government Area of Rivers State. The University of Port Harcourt, is an institution of higher learning owned by the Federal Republic of Nigeria, located in a strategic point along the popular east west road in Choba community, a community 20KM northwest of the garden city of Port Harcourt, the oil and gas capital of Nigeria. The university is a foremost center of teaching and research in the oil rich Niger Delta region of Nigeria. It was established in 1975 as a College of the University of Lagos and attained the full status as a university in 1977 when it gained full autonomy from the University of Lagos. (Ajienka, 2013).

\subsection{Study Population}

The population of the study site comprises 16500 (55\%) registered female undergraduate students excluding female students from the Faculty of Health Sciences for purpose of bias.

\subsection{Sample Size}

The sample size of this study comprised 330 female students drawn from seven faculties which are Administration, Agriculture, Arts, Humanities, Education, Engineering/ Technical Environment, and Social Sciences. The sample size was determined using Fischer formula (Araoye, 2003):

$\mathrm{n}=\mathrm{Z}^{2} \mathrm{pq} / \mathrm{e}^{2}$.

$\mathrm{n}=$ minimum sample size

$\mathrm{z}=$ standard normal derivative

$\mathrm{p}=$ proportion of sample population

$q=(1-p)$

$\mathrm{e}=$ level of precision

Approximately 300 was calculated but for reliability or non-response, $10 \%$ was added $300+30=330$

\subsection{Inclusion Criteria}

Only female respondents who filled and submitted their questionnaire were included in the study.

\subsection{Exclusion Criteria}

All male students of the study site and students offering medical and health related courses were excluded from the study.

\subsection{Sampling Technique}

The Seven Faculties with Seventy three Departments were included in the study. Multistage sampling technique was employed to select the desired sample size. The first stage was clustering the departments by faculties. The second stage was to stratify the departments into study levels and taking $30 \%$ of each department. There were five study levels which were study level 100/year one, level 200/year two, level 300/year three, level 400/year four, and level 500/year five. Systematic random sampling was used to select $30 \%$ of females to get the sample frame.

\subsection{Instrument for Data Collection}

The material used for this study was a well structured closed ended questionnaire which was written in English language and designed from reviewed literature. The questionnaire consists of questions for demographic characteristics of students (Section A), which includes age, study level, marital status and religion. Section B tests the awareness and knowledge of cervical cancer of the respondents. It comprises ten sets of questions which require respondents to answer yes or no. 


\subsubsection{Section A: Socio Demographic Characteristics}

- What was your age (last birthday)? (a) $\leq 17$ (b) 18 -21 (c) $22-25$ (d) 26-29 (e) $\geq 30$

- What is your level of study? (a) 100 level/ Year 1 (b) 200 level/Year 2 (c) 300 level/Year 3 (d) 400 level / Year 4 (e) 500 level / Year 53) What is your marital status: (a) Single (b) married (c) Separated (d) Divorced (e) cohabiting?

- What is your religion affiliation: (a) Christianity (b) Muslim (c) African traditionalist

\subsubsection{Section B: Awareness of cervical cancer}

- Have you ever heard of cervical cancer? (a) Yes (b) No

- Can Human papilloma virus (HPV) infection predispose to cervical cancer? (a) Yes (b) No 7 ) Can cervical cancer be inherited? (a) Yes (b) No

- Can Sexually Transmitted Infections (STIs) cause cervical cancer? (a) Yes (b) No

- Can previous cancer on other sites cause cervical cancer? (a) Yes (b) No

- Is there a cure for cervical cancer? (a) Yes (b) No

- Is condom use a method of preventing cervical cancer? (a) Yes (b) No

- Is pain during sexual intercourse a symptom of cervical cancer? (a) Yes (b) No

- Have you ever heard of cervical cancer vaccination? (a) Yes (b) No

- Cervical cancer vaccination is one way to cure cervical cancer (a) Yes (b) No Knowledge of cervical cancer

- Have you ever heard of cervical cancer? (a) yes (b) no

- Can Human papilloma virus (HPV) infection predispose to cervical cancer? (a) yes (b) no

- Can cervical cancer be inherited? (a)yes (b) no (c) not sure

- Can Sexually Transmitted Infections (STIs) cause cervical cancer? (a)yes (b) no

- Can previous cancer on other sites cause cervical cancer? (b)yes (b) no

- Is there a cure for cervical cancer? (a)yes (b) no

- Is condom use a method of preventing cervical cancer? (a)yes (b) no

- Is pain during sexual intercourse a symptom of cervical cancer? (a)yes (b) no

- Have you ever heard of cervical cancer vaccination? (a) yes (b) no (c) not sure

- Cervical cancer vaccination is one way to cure cervical cancer (a)yes (b) no

\subsection{Validity of the Instrument}

To ensure validity of the questionnaire, it was structured with the specific research questions based on literature review. Reliability of the instrument was determined using pre-test method. 10 copies of the questionnaire were given to some respondents at the Rivers State University of Science and Technology Port Harcourt Nigeria. This Institution shared similar characteristics with the Institution that participated in this study. Combats test was used to test the reliability of the questionnaire and a reliability coefficient of 0.9 was obtained.

\subsection{Method of Data Collection}

The questionnaire was administered to consented female students who were recruited during their lecture hours on the University Campus. They were informed of the details of the study by the researcher and its importance to the control and elimination of cervical cancer among females. They were assured of absolute confidentiality of their information as it will only be for research purposes. All questionnaires were filled individually by respondents without external influence and collected after completion.

\subsection{Method of Data Analysis}

Data was entered and analyzed using statistical package for social sciences version 21 . Awareness and knowledge of respondents towards cervical cancer was determined and reported in the form of mean, proportions and percentages. Chi square test of significance was carried out to test for significance between variables for categorical data with the level of statistical significance set up at $\mathrm{P}>5 \%$ (0.05).

\subsection{Ethical Consideration and Informed Consent}

Institutional approval was obtained from the Ethical Committee of University of Port Harcourt Rivers State, Nigeria. Informed verbal consent was obtained from participants after been informed about the details of the study and its working methods. In order to ensure confidentiality and anonymity, names and address of the respondents were not included in the questionnaire. 


\section{Results}

\begin{tabular}{|c|c|c|}
\hline Variables (Age) & Frequency (n=330) & Percentage (\%) \\
\hline$\leq 17$ & 69 & 20.90 \\
\hline $18-21$ & 102 & 30.91 \\
\hline $22-25$ & 85 & $25-76$ \\
\hline $26-29$ & 44 & 13.33 \\
\hline $30-34$ & 30 & 9.09 \\
\hline
\end{tabular}

Table 1: Represent Socio-Demographic Characteristics of Respondents

\begin{tabular}{|c|c|c|}
\hline Variables (Level of study) & Frequency (n=330) & Percentage (\%) \\
\hline Level 1 & 106 & 32.12 \\
\hline Level 2 & 61 & 18.48 \\
\hline Level 3 & 56 & 16.97 \\
\hline Level 4 & 55 & 16.67 \\
\hline Level 5 & 52 & 15.76 \\
\hline
\end{tabular}

Table 2: Represent Level of Study of Respondents

\begin{tabular}{|c|c|c|}
\hline Variables (Level of study) & Frequency (n=330) & Percentage (\%) \\
\hline Single & 226 & 68.48 \\
\hline Married & 75 & 22.73 \\
\hline Separated & 15 & 16.67 \\
\hline Divorced & 52 & 15.76 \\
\hline
\end{tabular}

Table 3: Represent Marital Status of Respondents

\begin{tabular}{|c|c|c|}
\hline Variables (Level of study) & Frequency (n=330) & Percentage (\%) \\
\hline Christianity & 330 & 100 \\
\hline Islam & 00 & 0.00 \\
\hline African Traditional Religion & 00 & 0.00 \\
\hline
\end{tabular}

Table 4: Represent Religion of Respondents

\begin{tabular}{|c|c|}
\hline Variables & Knowledge Level Score on Cervical Cancer (n=330) \\
\hline Knowledge score (Total score 10) & $4.17 \pm 2.41$ \\
\hline Mean \pm SD & $113(34.24)$ \\
\hline Low Knowledge level (0-3) & $168(50.91)$ \\
\hline Average knowledge level (4-6) & $49(14.85)$ \\
\hline High knowledge Level (7-10) & $96.74(0.001)^{*}$ \\
\hline Chi-square $(\chi 2)$ (p-value) &
\end{tabular}

Table 5: Knowledge Score of Respondents on Cervical Cancer

*Statistically Significant $(\mathrm{P} \varangle 0.05)$

\begin{tabular}{|c|c|c|c|}
\hline Knowledge Variables & Response & Frequency & Percentage (\%) \\
\hline Ever heard of cervical cancer & Yes & 239 & 72.42 \\
\hline Human Papilloma Virus is a risk factor to cervical cancer & No & 91 & 27.58 \\
\hline Cervical cancer can be inherited & No & 96 & 29.09 \\
\hline & Yes & 135 & 70.91 \\
\hline Nexually transmitted diseases can cause cervical cancer & No & 195 & 40.91 \\
\hline Yes & 160 & 48.48 \\
\hline Nhancer & No & 170 & 51.52 \\
\hline & Yes & 57 & 17.27 \\
\hline Cervical cancer is curable & No & 273 & 82.73 \\
\hline & Yes & 235 & 71.21 \\
\hline Use of condoms can prevent cervical cancer & No & 95 & 28.79 \\
\hline & Yes & 104 & 31.52 \\
\hline & No & 226 & 68.48 \\
\hline
\end{tabular}




\begin{tabular}{|c|c|c|c|}
\hline Knowledge Variables & Response & Frequency & Percentage (\%) \\
\hline \multirow[t]{2}{*}{ Pain during sexual intercourse is a sign of cervical cancer } & Yes & 128 & 38.79 \\
\hline & No & 202 & 61.21 \\
\hline \multirow[t]{2}{*}{ Have heard of cervical cancer vaccination } & Yes & 150 & 45.45 \\
\hline & No & 180 & 54.55 \\
\hline \multirow[t]{2}{*}{$\begin{array}{l}\text { Aware that cervical cancer vaccination is a way of preventing } \\
\text { cervical cancer }\end{array}$} & Yes & 73 & 22.12 \\
\hline & No & 257 & 77.88 \\
\hline
\end{tabular}

Table 6: Represent Respondents Knowledge on Cervical Cancer (N=330)

\section{Discussion}

Cervical cancer can be prevented only if it can be detected early and this can be possible through screening, vaccination, creation of awareness and cervical cancer knowledge. This study showed an average level awareness (50.91\%) for cervical cancer which was statistically significant ( $p=0.05)$ Table 5. Age and Marital status (single) Table 1 and 3.3 has a statistical significance for knowledge $(p=0.05)$. The reason could be that teenagers are more accessible to information especially on social media. This reason is attributable to the report represented in Table 2 that showed highest frequency 106(32.12\%) of respondents in study level one. In Table6 of this study, $72.42 \%$ indicated that they have heard of cervical cancer. This result is considerably high compared to the result published by (Muhammadet al., 2014) where $55.2 \%$ was shown to have heard of cervical cancer. Out of this only $37.2 \%$ got the awareness from television. Also in a cross sectional survey of 650 women conducted in London showed that $76.2 \%$ had heard of cervical cancer. This finding is in line with this present study. A larger proportion of respondents $91.6 \%$ also indicated having heard of cervical cancer which was studied in Gabon.

In his survey, only $8 \%$ ware aware that HPV infection can predispose to cervical cancer. This is low when compared to this study where $29.09 \%$ of respondents indicated HPV infection as a predisposing factor to cervical cancer. None of the Malaysian women respondents (Wong et al., 2009).aged 21-56 years had heard of HPV. Only 19.0\% of adult Korean women reported to know that HPV infection was a risk factor for cervical cancer (Oh et al., 2010). In yet another Korean studies, a mere $9.5 \%$ of female high school and university students reported that they had ever heard of HPV (Han et al., 2007).

Also $48.48 \%$ know that sexually transmitted infections can predispose to cervical cancer. Only 19\% and 7\% of participants in a study by Cristina et al., (2010), knew that HPV is a Sexually Transmitted Infection (STI) and that it can cause cervical cancer respectively. Awareness for condom use as a means of preventing cervical cancer was $31.52 \%$. This low level of awareness of condom use is in contrast to the high level of awareness about STI shown by the respondents. It showed an awareness practice disconnect which can be promoting the transmission of sexually transmitted diseases within the population. It establishes a strong reason for health education, awareness and cervical cancer knowledge in the population. Table 3.4 showed 100\% religion for Christianity. However it did not translate to respondent's practice for sexual activities.

Awareness on having heard of cervical cancer and cervical cancer vaccination as a way of preventing cervical cancer was reported in this study as $45.45 \%$ and $22.12 \%$ respectively. This result is in line with the report of Mouallifet al., (2014) 14.3\% and Pandeyet al., (2013) 28.1\% for vaccination as a way of preventing cervical cancer. Amos et al., (2015) reported that $70 \%$ of the respondents know that cervical cancer can be prevented and $92 \%$ declared that it can be cured if diagnosed early. Awareness on symptom of cervical cancer for bleeding after intercourse was reported as $38.79 \%$. This awareness level is a little higher than that reported by Priyan (11\%) in India.

The average level of knowledge and awareness recorded for cervical cancer is similar to the studies conducted in Nigeria by Ojimah \& Maduka(2017), Enzenwaet al., (2013), Kola et al., (2013) \& Illiyasuet al., (2010). These reports may be true reflection of respondent's activity and practice towards cervical cancer.

\section{Conclusion}

It is important for parents especially mothers to educate their daughters on the benefits of cervical cancer vaccination and hence encourage them to take it before they become sexually matured. Government and Non Governmental agencies should formulate policies to strengthen cervical cancer education through the media and social network. A national cervical cancer algorithm will also improve the current situation.

\section{Recommendations.}

- All women of child bearing age should endeavor to screen for cervical cancer.

- Women should also practice cervical cancer prevention activities such as maintaining single sexual partner

- Formation of cervical cancer clubs at primary and post primary school level will greatly provide baseline information for women who may be at risk of cervical cancer.

- There should also be a pre-school admission cervical screening exercise for all females.

\section{Acknowledgement}

Our sincere appreciation goes to Dr. (Mrs.) Dorcas Orabelema who helped to edit the work. 


\section{References}

i. Araoye, M, O. (2003). Sample Size determination. In: Research methodology with Statistics for Health and Social Sciences.Ilorin: Nathadex.

ii. Masood S. (1999). A plea for a worldwide volunteer cervical cancer education and awareness program. Acta Cytology. 43:539-42.

iii. Goroll AH, May LA, Mulley AG. (1995). Primary care medicine: Office evaluation and management of the adult patient. Screening for cervical cancer.588-590

iv. Pisani P, Parkin DM, Bray F, Ferley J. (1999). Estimates of the worldwide mortality from 25 cancers. International Journal of Cancer. 83:870-3.

v. Walboomers JM, Jacobs MV, Manos MM, et al. (1999). Human papillomavirus is a necessary cause of invasive caner worldwide. Journal of Pathology. 189:12-9.

vi. Munoz N, Bosch FX, de Sanjose S, Herrero R, Castellsague X, Shah VK et al.(2003). Epidemiologic classification of human papillomavirus types associated with cervical cancer. New England Journal of Medicine. 2003; 348(6): 518-27.

vii. Anorlu RI. (2008).What is the significance of the HPV epidemic. Canadian Journal of Urology. 15(1): 3860-5.

viii. World Health Organization (2010). Information Centre on HPV and Cervical Cancer (HPV Information Centre). Human Papilloma virus and Related Cancers in Nigeria. Summary Report. Comprehensive cancer control: a guide to essential practice. 2006. Geneva Switzerland.

ix. Hendricks KA. (2003). Re: "Genital human papillomavirus infection: incidence and risk factors in a cohort of female university students". American Journal of Epidemiology. 158(9): 927.

x. World Health Organization (2006). Guidelines for cervical cancer screening programme. Government of IndiaWorld Health Organization Collaborative Programme (2004-2005). Chandigarh, India: postgraduate Institute of Medical Education and Research.

xi. Lenselink CH, Schmeink CE, Melchers WJ, Massuger LF, Hendriks JC, van Hamont D et al. (2008).Young adults and Acceptance of the Human Papillomavirus Vaccine. Journal of Public Health. 122(12): 1295-1301.

xii. Muhammad E H., Shanaz G, Roger C, \& Guido V H. (2004). Cervical Cancer Screening among University Students in South Africa: A Theory Based Study. PLoSONE:9(11)

xiii. Wong LP, Wong YL, Low WY, Khoo EM, \& Shuib R. (2009). Knowledge and awareness of cervical cancer and screening among Malaysian women who have never had a Pap smear: a qualitative study. Singapore Medical Journal; $.50(1): 49-53$.

xiv. Oh JK, Lim MK, Yun EH, Lee EH, Shin HR. (2010). Awareness of and attitude towards human papillomavirus infection and vaccination for cervical cancer prevention among adult males and females in Korea: a nationwide interview survey.Vaccine. 17;28(7):1854-60.

xv. Han, Y.J., Lee, S.R., Kang, E.J.et al. (2007). Knowledge regarding cervical cancer, human papillomavirus and future acceptance of vaccination among girls in their late teens in Korea. Korean Journal of Obstetrics\&Gynecology; 50:1090-9.

xvi. Christina, M., Hernández, R.N.\& Debra, W. (2014). A Profile of Mexican-born Women Who Adhere to National Cervical Cancer Screening Recommendations. Journal of Community Health Nursing: 31(3): 157-166.

xvii. Mouallif, M., Bowyer, H.L., Festali, S., Alber,t A., Filali-Zegzouti, Y., Guenin, S., Delvenne, P., Waller, J., \&Ennaji, M.M. (1014). Cervical cancer and HPV: Awareness and vaccine acceptability among parents in Morocco. Vaccine. 9;32(3):409-16.

xviii. Pandey, R .A. \& Era, K. (2017).Cervical cancer screening behavior and associated factors among women of UgrachandiNala, Kavre, Nepal.European Journal of Medical Research. 22: 32.

xix. Amos, D. M, M., Christohper, G O., Edward, M. W., Georgios, L., Henry, W.\& Martin R. (2015). Awareness of cervical cancer risk factors and symptoms: cross-sectional community survey in post-conflict northern Uganda. Health Expectations. 19(4): 854-867.

xx. Ojumah, C, \&Maduka, O. (2017). Awareness and uptake of human papilloma virus vaccines among female undergraduate students: Implications for cervical cancer prevention in South-South, Nigeria. Port Harcourt Medical Journal. 11: 134-40

xxi. Ezenwa, B.N., Balogun, M.R., Okafor, I.P. (2013). Mothers' human papilloma virus knowledge and willingness to vaccinate their adolescent daughters in Lagos, Nigerian International Journal Women's Health. 5:371-7.

xxii. Kola, M.O., Adeola, F.A., Lawrence, A.A., Oluseyi,O.A. (2013). Human papillomavirus vaccine: Knowledge, attitude and perception of parents in Southwest Nigeria. Medical Science Public Health. 1:13-9.

xxiii. Iliyasu, Z., Abubakar, I.S., Aliyu, M.H., Galadanci, H.S. (2010). Cervical cancer risk perception and predictors of human papilloma virus vaccine acceptance among female university students in Northern Nigeria. Journal of Obstetrics \&Gynaecology.30:857-62. 